\title{
Comparison of outcome measures from different pathways following total knee arthroplasty
}

\author{
Hiok Yang Chan, MBBS $^{1}$, Rehena Sultana ${ }^{2}$, Seng Jin Yeo ${ }^{1}$, MBBS, FRCS, Shi-Lu Chia $^{1}$, MBBS, FRCS,
} Hee Nee Pang${ }^{1}$, MBBS, fRCS, Ngai Nung $\underline{L O}^{1}$, MBBS, fRCS

INTRODUCTION The benefits of extended inpatient rehabilitation following total knee arthroplasty (TKA) in local community hospitals ( $\mathrm{CHs}$ ) are unproven. Our study compared functional outcomes between patients discharged home and to $\mathrm{CHs}$ following TKA.

METHODS A case-control study was conducted of patients undergoing primary unilateral TKA. Consecutive patients ( $n=1,065)$ were retrospectively reviewed using the Knee Society Clinical Rating System (KSCRS), 36-item Short Form Health Survey (SF-36) and Oxford Knee Score (OKS) preoperatively, and at the six-month and two-year follow-ups.

RESULTS Overall, 967 (90.8\%) patients were discharged home and $98(9.2 \%)$ to $\mathrm{CHs}$. CH patients were older (mean age 70.7 vs. 67.2 years; $p<0.0001)$, female ( $86.7 \%$ vs. $77.5 \% ; p=0.0388$ ) and less educated (primary education and above: $61.7 \%$ vs. $73.8 \% ; \mathrm{p}=0.0081$ ). Median $\mathrm{CH}$ length of stay was 23.0 (range 17.0-32.0) days. Significant predictors of discharge destination were older age, female gender, lower education, and poorer ambulatory status and physical health. Preoperatively, $\mathrm{CH}$ patients had worse KSCRS Function (49.2 \pm 19.5 vs. $54.4 \pm 16.8 ; \mathrm{p}=0.0201)$, SF-36 Physical Functioning ( $34.3 \pm 22.6$ vs. $40.4 \pm 22.2 ; p=0.0017)$ and Social Functioning $(48.2 \pm 35.1$ vs. $56.0 \pm 35.6 ; p=0.0447)$ scores. $\mathrm{CH}$ patients had less improvement for all scores at all follow-ups. Regardless of preoperative confounders, with repeated analysis of variance, discharge destination was significantly associated with KSCRS, SF-36 and OKS scores. CONCLUSION Older, female and less educated patients with poorer preoperative functional scores were more likely to be discharged to $\mathrm{CHs}$ after TKA. At the two-year follow-up, patients in $\mathrm{CHs}$ had less improvement in functional outcomes than those discharged home.

Keywords: community hospital, discharge location, functional outcomes, rehabilitation, total knee arthroplasty

\section{INTRODUCTION}

Osteoarthritis, reported to be a significant burden in the global population, has been estimated to be the fourth leading cause of disability and the precipitating diagnosis for more than $90 \%$ of the total knee arthroplasty (TKA) operations performed globally. ${ }^{(1-4)}$ TKA provides excellent improvement in physical function and pain..$^{(1-4)}$

Following TKA surgery, patients are placed on a discharge pathway. They are either discharged home or to community hospitals (CHs) for continued subacute care. In Singapore, $\mathrm{CHs}$ are rehabilitation facilities that provide 24-hour care and assistance in activities of daily living with the help of doctors, nurses and therapists, similar to skilled nursing facilities, inpatient rehabilitation or subacute rehabilitation in Western countries. ${ }^{(5-11)}$ Reasons for discharging patients to step-down care in $\mathrm{CHs}$ include insufficient function to return to the home environment or workforce, lack of caregiving at home and inability to conduct rehabilitation at home, thus requiring extended supervision. However, there are no defined criteria for continued care in $\mathrm{CHs}$, and the discharge destination depends on both surgeon and patient evaluations on a case-by-case basis. The rehabilitation programmes differ between countries in terms of the level of intensity and amount of resources available. ${ }^{(12)}$

Several overseas studies comparing rehabilitation at home with that in skilled nursing facilities have shown that rehabilitation at home has no difference or significantly better functional outcomes when compared to rehabilitation in nursing facilities. ${ }^{(6-11)}$ In our local context, demand for subacute care in $\mathrm{CHs}$ has increased in recent years, with decreasing length of stay (LOS) following TKA and improved quality of rehabilitation in CHs. ${ }^{(13)}$ However, there is a paucity of literature comparing the benefits of inpatient subacute rehabilitation after TKA in $\mathrm{CHs}$ versus outpatient rehabilitation.

The primary aim of this study was to assess the difference in functional outcomes between two distinct discharge pathways, where patients who underwent primary unilateral TKA due to osteoarthritis were either discharged home or to $\mathrm{CHs}$. The secondary aim was to identify differences in demographic characteristics between these two groups of patients.

\section{METHODS}

Inclusion criteria were patients who underwent primary unilateral TKA and had a primary diagnosis of osteoarthritis. Exclusion criteria were patients who underwent revision TKA or contralateral leg TKA within two years of primary TKA, or did not complete at least six months of follow-up. No funding was required for this project. The study was approved by the hospital ethics review board and written informed consent was obtained from all recruited patients.

${ }^{1}$ Department of Orthopaedic Surgery, Singapore General Hospital, ${ }^{2}$ Centre for Quantitative Medicine, Duke-NUS Medical School, Singapore 
Patients were identified by using the diagnostic codes available in the electronic hospital inpatient discharge summaries. In all, 1,338 patients were enrolled for primary unilateral TKA at the orthopaedics department in Singapore General Hospital, Singapore, from January 2012 to November 2012. Of these, 218 patients were excluded because they had either contralateral TKA during the follow-up period $(\mathrm{n}=210$ ) or significant postoperative complications (e.g. periprosthetic fracture, aseptic loosening, nerve palsies, postoperative infection) that required revision ( $\mathrm{n}=8$ ). In addition, 55 patients did not complete the mandatory six-month follow-up; therefore, only 1,065 patients were included in the final analyses.

Accordingly, this was a case-control study with 1,065 patients. Patients and controls were defined based on their discharge destination following TKA: 98 patients were discharged to $\mathrm{CHs}$ and 967 controls were discharged home (Fig. 1). All had at least six months of follow-up. However, only 78 patients and 801 controls completed the two-year follow-up. Patients were discharged to five different $\mathrm{CHs}$, each having a similar designated rehabilitation department for postsurgical patients.

Patients were started on rehabilitation in $\mathrm{CH}$ s on Postoperative Day (PD) 1, with early mobilisation as the priority, aiming toward total weight bearing. ${ }^{(14)}$ As a general rule, physical rehabilitation was aimed at getting patients to ambulate $30 \mathrm{~m}$ independently with minimal aid, climb four steps independently and have a knee range of $0^{\circ}-90^{\circ}$ by $\mathrm{PD} 3 .^{(15-17)}$ This is regarded locally as the standard pathway to postoperative care of TKA patients, as it reduces postoperative complications and maximises function. All TKA patients were assessed by a multidisciplinary team of physiotherapists and orthopaedic surgeons to have achieved the appropriate standard in physical function before being deemed suitable for discharge home or to $\mathrm{CHs}$, with a walking aid for the first month or as required. According to the local protocol, patients in $\mathrm{CHs}$ undergo inpatient rehabilitation consisting of supervised physiotherapy daily or every other day for about one hour until the day of discharge. Those discharged home go for regular visits to an outpatient rehabilitation centre for supervised physiotherapy of about one hour, with decreasing frequency as functional status improves. Patients are also taught lower limbstrengthening exercises for continued rehabilitation on days without supervised physiotherapy. ${ }^{(18)}$

Baseline demographic characteristics (e.g. age, gender and education), comorbidities (e.g. diabetes mellitus, hypertension, hyperlipidaemia, gout, dementia, rheumatoid arthritis, cerebrovascular accident, Parkinson's disease, asthma and depression), severity of osteoarthritis, postsurgical complications, post-TKA LOS in the hospital and LOS in $\mathrm{CH}$ s were recorded. Outcome variables were functional outcome scores of patients discharged home and to $\mathrm{CHs}$, measured at three different time points (preoperatively, and at six months and two years postoperatively), based on the Knee Society Clinical Rating System (KSCRS), 36-item Short Form Health Survey (SF-36) and Oxford Knee Score (OKS). Using these three scoring systems, trained technicians and physiotherapists conducted the interviews in person to ascertain patient function and quality of life, two

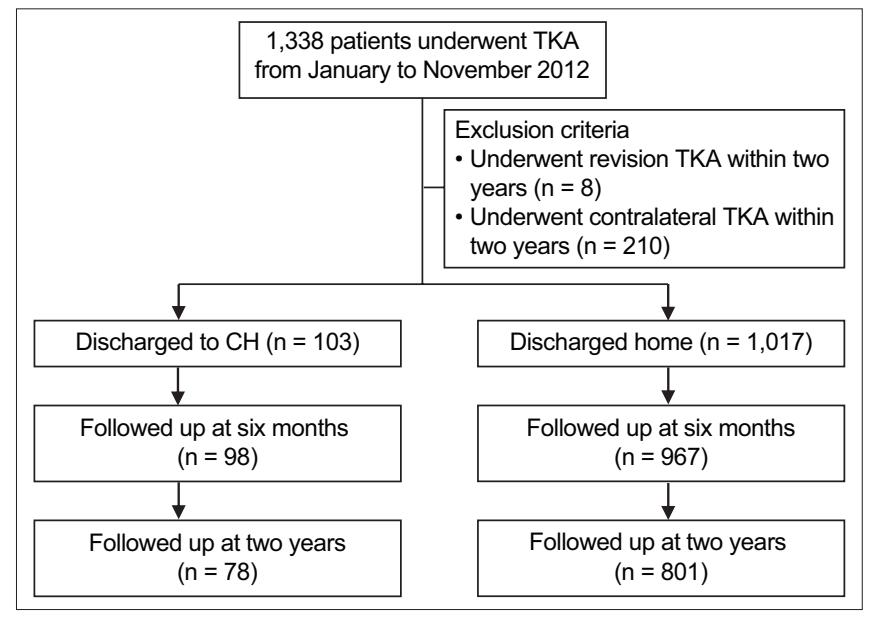

Fig. 1 Flowchart shows patients discharged home and to community hospital $(\mathrm{CH})$ after total knee arthroplasty (TKA) over a two-year followup period.

weeks prior to the surgery for preoperative measurements, and at six months and two years, after surgery for postoperative measurements.

The KSCRS has two components - Function and Knee - both ranging from 0 to 100, with a higher score indicating better knee function. The OKS is a 12-item questionnaire that measures the patient's pain and physical disability. The overall score ranges from 12 to 60, with a higher score indicating more severe knee problems. The SF-36 is a general health status questionnaire that has 36 questions measuring eight health dimensions, in terms of energy level: Physical Functioning; role limitations due to physical health problems (Role Functioning Physical); pain level and frequency (Pain); General Health; Mental Health; role limitations due to emotional problems (Role Functioning Emotional); Social Functioning; and Vitality. 100 points are allocated to each health dimension, with a higher score indicating a better functional outcome. The SF-36 and OKS have been validated in Singapore by previous orthopaedics studies. ${ }^{(19-21)}$

Demographic and clinical characteristics were summarised as mean \pm standard deviation for continuous variables and as frequency with corresponding proportion for categorical variables. Variables were categorised based on post-TKA destinations (home or $\mathrm{CH}$ ). Post-TKA destinations were compared using the Kruskal-Wallis non-parametric test for continuous variables and Fisher's exact test for categorical variables. Predictors of postTKA destination were identified using univariate and multivariate logistic regression analyses. Associations found during logistic regression analysis were expressed as odds ratios (ORs) with 95\% confidence intervals (Cls). Repeated measurements of KSCRS, SF-36 and OKS were compared between post-TKA destinations using repeated analysis of variance (ANOVA) while adjusting for potential confounders (e.g. age, gender, educational level and presence of any comorbidities over the follow-up period). A p-value $<0.05$ was considered to be statistically significant and all tests were two-tailed. SAS version 9.3 (SAS Institute, Cary, NC, USA) was used for analysis.

For power calculation, the minimal clinically important change for SF-36 Physical Functioning was defined as 10, in 
Table I. Preoperative findings of patients discharged home and to community hospitals (CHs) following total knee arthroplasty $(n=1,065)$.

\begin{tabular}{|c|c|c|c|}
\hline \multirow[t]{2}{*}{ Variable } & \multicolumn{2}{|c|}{ Mean \pm SD/no. (\%) } & \multirow[t]{2}{*}{ p-value } \\
\hline & Home $(n=967)$ & $\mathrm{CH}(n=98)$ & \\
\hline Age (yr) & $67.2 \pm 7.8$ & $70.7 \pm 7.6$ & $<0.0001$ \\
\hline Female gender & $749(77.5)$ & 85 (86.7) & 0.0388 \\
\hline Education* & & & 0.0081 \\
\hline None & $239(26.2)$ & $36(38.3)$ & \\
\hline Primary & $318(34.8)$ & $37(39.4)$ & \\
\hline Secondary & $283(31.0)$ & $18(19.1)$ & \\
\hline Tertiary & $73(8.0)$ & $3(3.2)$ & \\
\hline Body mass index $\left(\mathrm{kg} / \mathrm{m}^{2}\right)$ & $27.9 \pm 4.8$ & $27.3 \pm 5.0$ & 0.2725 \\
\hline Ethnicity & & & 0.4190 \\
\hline Chinese & $846(87.5)$ & $84(85.7)$ & \\
\hline Malay & $64(6.6)$ & $5(5.1)$ & \\
\hline Indian & $44(4.6)$ & $8(8.2)$ & \\
\hline Other & $13(1.3)$ & $1(1.0)$ & \\
\hline Comorbidity $^{+}$ & & & 0.2113 \\
\hline 0 & $236(24.4)$ & $22(22.4)$ & \\
\hline 1 & $562(58.1)$ & $65(66.3)$ & \\
\hline$\geq 2$ & $169(17.5)$ & $11(11.2)$ & \\
\hline Complication $^{\ddagger}$ & & & 0.0987 \\
\hline No & $932(96.4)$ & $91(92.9)$ & \\
\hline Yes & $35(3.6)$ & $7(7.1)$ & \\
\hline \multicolumn{4}{|l|}{ KSCRS domain score } \\
\hline Function & $54.4 \pm 16.8$ & $49.2 \pm 19.5$ & 0.0201 \\
\hline Knee & $39.6 \pm 18.1$ & $38.5 \pm 18.2$ & 0.5578 \\
\hline \multicolumn{4}{|l|}{ SF-36 domain score } \\
\hline Physical Functioning & $40.4 \pm 22.2$ & $34.3 \pm 22.6$ & 0.0017 \\
\hline Role Functioning Physical & $23.9 \pm 36.6$ & $23.7 \pm 36.5$ & 0.9970 \\
\hline Pain & $37.2 \pm 17.5$ & $36.4 \pm 19.4$ & 0.6009 \\
\hline General Health & $71.9 \pm 18.7$ & $72.3 \pm 17.6$ & 0.9837 \\
\hline Vitality & $71.2 \pm 20.8$ & $68.5 \pm 19.4$ & 0.0561 \\
\hline Social Functioning & $56.0 \pm 35.6$ & $48.2 \pm 35.1$ & 0.0447 \\
\hline Role Functioning Emotional & $84.8 \pm 35.2$ & $84.0 \pm 35.6$ & 0.8022 \\
\hline Mental Health & $79.9 \pm 16.8$ & $77.4 \pm 16.9$ & 0.1144 \\
\hline OKS & $34.2 \pm 7.9$ & $35.8 \pm 8.4$ & 0.0721 \\
\hline LOS in CH" (day) & - & $23.0(17.0-32.0)$ & \\
\hline
\end{tabular}

*Data excluded that of 54 patients discharged home and 4 patients discharged to $\mathrm{CHs}$ due to incomplete data collection and uncontactable patients. †ncludes diabetes mellitus, hypertension, hyperlipidaemia, gout, dementia, rheumatoid arthritis, cerebrovascular accident, Parkinson's disease, asthma and depression. ¥Includes periprosthetic fracture/dislocation, aseptic loosening, periprosthetic septic arthritis, wound infection and stiffness. १Data presented as median (range). KSCRS: Knee Society Clinical Rating System; LOS: length of stay; OKS: Oxford Knee Score; SD: standard deviation; SF-36: 36-item Short Form Health Survey

keeping with the definition by Escobar et al. ${ }^{(22)}$ We found that the required sample size (with $80 \%$ power, $\alpha=0.05$ and $1: 1$ allocation ratio for case:control) was 82 (variance $=22.6$ and variance ratio $=1$ ) for the patient and control groups.

\section{RESULTS}

Patients discharged to $\mathrm{CHs}$, as compared to those discharged home, were older (mean age: $70.7 \pm 7.6$ vs. $67.2 \pm 7.8$ years; $\mathrm{p}<0.0001$ ), less educated (primary education and above: $61.7 \%$ vs. $73.8 \%$; p $=0.0081)$, female $(86.7 \%$ vs. $77.5 \%$; $\mathrm{p}=0.0388)$, and had lower mean KSCRS Function (49.2 \pm 19.5 vs. $54.4 \pm 16.8 ; p=0.0201), p=0.0201)$, SF-36 Physical Functioning
$(34.3 \pm 22.6$ vs. $40.4 \pm 22.2 ; p=0.0017)$ and SF-36 Social Functioning (48.2 \pm 35.1 vs. $56.0 \pm 35.6 ; p=0.0447)$ scores. There was no statistically significant difference between patients discharged home and those discharged to $\mathrm{CHs}$ with respect to ethnicity, body mass index, comorbidities and postoperative complications. Median LOS in CHs was 23.0 (range 17.0-32.0) days (Table I).

Univariate logistic regression analysis showed that older age (OR 1.06, 95\% Cl 1.03-1.09; $p<0.0001)$, female gender (OR $1.90,95 \% \mathrm{Cl} 1.04-3.48 ; \mathrm{p}=0.0364)$, lower education (OR 2.20, $95 \% \mathrm{Cl} 1.30-3.70 ; \mathrm{p}=0.0114)$, and lower preoperative KSCRS Function (OR 0.98, 95\% Cl 0.97-1.00; $p=0.0049$ ), SF-36 Physical 




Fig. 2 Chart shows mean scores of SF-36 over two years for home and community hospital patients who underwent total knee arthroplasty. ${ }^{*}$ Difference between home and community hospital patients was statistically significant $(p<0.05)$. GH: General Health; MH: Mental Health; PF: Physical Functioning; RFE: role limitations due to emotional problems (Role Functioning Emotional); RFP: role limitations due to physical health problems (Role Functioning Physical); SF: Social Functioning; SF-36: 36-item Short Form Health Survey

Table II. Univariate logistic regression analysis for association between preoperative findings and probability of discharge to community hospitals.

\begin{tabular}{|lll|}
\hline Variable & OR (95\% Cl) & p-value \\
\hline Age & $1.06(1.03-1.09)$ & $<0.0001$ \\
\hline Gender (reference: male) & $1.90(1.04-3.48)$ & 0.0364 \\
\hline Education (reference: tertiary) & $2.20(1.30-3.70)$ & $0.0114^{*}$ \\
\hline None & $3.66(1.10-12.24)$ & 0.0045 \\
\hline Primary & $2.83(0.85-9.43)$ & 0.0999 \\
\hline Secondary & $1.55(0.44-5.39)$ & 0.2884 \\
\hline Body mass index & $0.97(0.93-1.02)$ & 0.2521 \\
\hline KSCRS domain score & & \\
\hline Function & $0.98(0.97-1.00)$ & 0.0049 \\
\hline Knee & $1.00(0.98-1.01)$ & 0.5366 \\
\hline SF-36 domain score & & \\
\hline Physical Functioning & $0.99(0.98-1.00)$ & 0.0111 \\
\hline Role Functioning Physical & $1.00(0.99-1.01)$ & 0.9719 \\
\hline Pain & $1.00(0.99-1.01)$ & 0.6723 \\
\hline General Health & $1.00(0.99-1.01)$ & 0.8486 \\
\hline Vitality & $0.99(0.98-1.00)$ & 0.2151 \\
\hline Social Functioning & $0.99(0.99-1.00)$ & 0.0400 \\
\hline Role Functioning Emotional & $1.00(0.99-1.01)$ & 0.8366 \\
\hline Mental Health & $0.99(0.98-1.00)$ & 0.1657 \\
\hline OKS & $1.02(1.00-1.05)$ & 0.0666 \\
\hline Comorbidity (reference: no) & $1.67(0.88-3.20)$ & 0.1192 \\
\hline
\end{tabular}

*Refers to type III p-value. Cl: confidence interval; KSCRS: Knee Society Clinica Rating System; OKS: Oxford Knee Score; OR: odds ratio; SF-36: 36-item Short Form Health Survey

Functioning (OR 0.99, 95\% Cl 0.98-1.00; $\mathrm{p}=0.0111$ ) and SF36 Social Functioning (OR 0.99, 95\% Cl 0.99-1.00; $p=0.0400$ ) scores were significantly associated with being discharged to $\mathrm{CHs}$ following TKA (Table II). Multivariate logistic regression analysis did not show an association between post-TKA discharge destination and the other covariates.

For both group of patients, all scores for KSCRS, SF-36 and OKS demonstrated an improving trend from pre-TKA to the six-month and two-year follow-ups. Post-TKA scores of all KSCRS, SF-36 and OKS components at the six-month and two-year follow-ups were generally better for patients discharged home compared to those discharged to $\mathrm{CHs}$. At the six-month follow-up, patients discharged home did significantly better in terms of mean scores for KSCRS Function (71.0 vs. 62.3; $\mathrm{p}<0.0001)$ and OKS (19.6 vs. 21.5; $p=0.0030)$, as well as in these SF-36 domains: Physical Functioning (66.9 vs. 59.1; $p=0.0004)$; Role Functioning Physical (72.7 vs. 64.0; $p=0.0361$ ); Pain (70.1 vs. 63.4; $p=0.0102$ ); Social Functioning (88.1 vs. 81.4; $p=0.0162$ ); and Mental Health (84.8 vs. 81.6; $\mathrm{p}=0.0467)$.

At the two-year follow-up, patients discharged home again performed significantly better (Table III, Figs. 2 \& 3) in terms of mean scores for KSCRS Function (73.9 vs. 60.9; $p<0.0001)$ and Knee (85.1 vs. 80.7; $p=0.0035)$, OKS (18.5 vs. 22.0; $p<0.0001$ ), as well as SF-36 Physical Functioning (69.5 vs. 57.2; $p<0.0001$ ), Role Functioning Physical (72.6 vs. 58.4; $\mathrm{p}=0.0014$ ), Pain (69.4 vs. 63.3; $p=0.0394)$, General Health (72.1 vs. 66.9; $\mathrm{p}=0.0340)$ and Social Functioning (88.3 vs. 80.9; $\mathrm{p}=0.0142$ ).

The degree of improvement in the functional outcomes of $\mathrm{CH}$ and home patients at the six-month and two-year follow-ups was compared with respect to their preoperative status. Patients discharged home had greater improvement in SF-36 Pain (33.0 vs. 27.0; $p=0.0346)$ scores at the six-month follow-up. There were no differences in improvement in the functional scores from preoperative levels to the six-month follow-up for OKS and KSCRS. At the two-year follow-up, patients discharged home had significantly more improvement from preoperative levels for KSCRS Function (19.5 vs. 11.6; $p=0.0004$ ), and SF-36 Physical Functioning 
Table III. Functional outcome measures of patients discharged home and to community hospitals (CHs) following total knee arthroplasty over the study period.

\begin{tabular}{|c|c|c|c|}
\hline \multirow[t]{2}{*}{ Variable } & \multicolumn{3}{|c|}{ Mean $(95 \% \mathrm{Cl})$} \\
\hline & Preoperative & 6-mth follow-up (n=1,065) & 2-yr follow-up ( $n=879)$ \\
\hline \multicolumn{4}{|l|}{ KSCRS domain } \\
\hline \multicolumn{4}{|l|}{ Function } \\
\hline Home & 54.4 (53.3 to 55.4$)$ & 71.0 (69.9 to 72.1$)$ & 73.9 (72.6 to 75.2 ) \\
\hline $\mathrm{CH}$ & 49.2 (45.9 to 52.6$)$ & 62.3 (58.8 to 65.9 ) & $60.9(56.7$ to 65.1$)$ \\
\hline Difference & $-5.1(-8.7$ to -1.6$)$ & $-8.7(-12.4$ to -4.9$)$ & $-13.0(-17.4$ to -8.6$)$ \\
\hline$p$-value & $0.0047^{*}$ & $<0.0001^{*}$ & $<0.0001^{*}$ \\
\hline \multicolumn{4}{|l|}{ Knee } \\
\hline Home & 39.6 (38.5 to 40.8$)$ & 84.6 (83.8 to 85.4$)$ & 85.1 (84.2 to 86.0$)$ \\
\hline $\mathrm{CH}$ & 38.5 (34.9 to 42.0 ) & 82.2 (79.7 to 84.7 ) & 80.7 (77.9 to 83.5$)$ \\
\hline Difference & $-1.2(-5.0$ to 2.6$)$ & $-2.4(-5.1$ to 0.2$)$ & $-4.4(-7.3$ to -1.4$)$ \\
\hline$p$-value & 0.5353 & 0.0712 & $0.0035^{*}$ \\
\hline \multicolumn{4}{|l|}{ SF-36 domain } \\
\hline \multicolumn{4}{|c|}{ Physical Functioning } \\
\hline Home & 40.4 (39.0 to 41.8$)$ & 66.9 (65.6 to 68.2$)$ & 69.5 (67.9 to 71.0$)$ \\
\hline $\mathrm{CH}$ & 34.3 (29.9 to 38.8 ) & 59.1 (55.0 to 63.1) & $57.2(52.2$ to 62.1$)$ \\
\hline Difference & $-6.0(-10.7$ to -1.4$)$ & $-7.8(-12.0$ to -3.5$)$ & $-12.3(-17.5$ to -7.1$)$ \\
\hline$p$-value & $0.0106^{*}$ & $0.0004^{*}$ & $<0.0001^{*}$ \\
\hline \multicolumn{4}{|c|}{ Role Functioning Physical } \\
\hline Home & 23.9 (21.5 to 26.2$)$ & 72.7 (70.2 to 75.1$)$ & 72.6 (70.0 to 75.2$)$ \\
\hline $\mathrm{CH}$ & 23.7 (16.5 to 31.0$)$ & 64.0 (56.3 to 71.7$)$ & 58.4 (50.0 to 66.7 ) \\
\hline Difference & $-0.1(-7.7$ to 7.5$)$ & $-8.6(-16.7$ to -0.6$)$ & $-14.2(-23.0$ to -5.5$)$ \\
\hline$p$-value & 0.9749 & $0.0361^{*}$ & $0.0014^{*}$ \\
\hline \multicolumn{4}{|l|}{ Pain } \\
\hline Home & 37.2 (36.0 to 38.3 ) & 70.1 (68.5 to 71.7) & 69.4 (67.7 to 71.1$)$ \\
\hline $\mathrm{CH}$ & 36.4 (32.9 to 39.9 ) & 63.4 (58.5 to 68.3 ) & 63.3 (57.7 to 68.8 ) \\
\hline Difference & $-0.8(-4.5$ to 2.9$)$ & $-6.7(-11.9$ to -1.6$)$ & $-6.1(-12.0$ to -0.3$)$ \\
\hline$p$-value & 0.6753 & $0.0102^{*}$ & $0.0394^{*}$ \\
\hline \multicolumn{4}{|c|}{ General Health } \\
\hline Home & 71.9 (70.8 to 73.1$)$ & 71.0 (69.7 to 72.3 ) & 72.1 (70.7 to 73.5 ) \\
\hline $\mathrm{CH}$ & 72.3 (68.6 to 76.0 ) & 70.7 (66.8 to 74.7 ) & 66.9 (62.3 to 71.5$)$ \\
\hline Difference & $0.4(-3.5$ to 4.2$)$ & $-0.3(-4.5$ to 3.9$)$ & $-5.2(-10.0$ to -0.4$)$ \\
\hline$p$-value & 0.8520 & 0.8946 & $0.0340^{*}$ \\
\hline \multicolumn{4}{|l|}{ Vitality } \\
\hline Home & 71.2 (69.9 to 72.5 ) & 74.9 (73.6 to 76.1$)$ & 75.7 (74.2 to 77.1$)$ \\
\hline $\mathrm{CH}$ & 68.5 (64.4 to 72.6 ) & 71.7 (67.8 to 75.5 ) & 73.7 (69.2 to 78.3 ) \\
\hline Difference & $-2.7(-7.0$ to 1.6$)$ & $-3.2(-7.2$ to 0.9$)$ & $-1.9(-6.7$ to 2.8$)$ \\
\hline$p$-value & 0.2138 & 0.1255 & 0.4260 \\
\hline \multicolumn{4}{|c|}{ Social Functioning } \\
\hline Home & 56.0 (53.8 to 58.3 ) & 88.1 (86.4 to 89.7 ) & 88.3 (86.6 to 90.1 ) \\
\hline $\mathrm{CH}$ & 48.2 (41.2 to 55.3 ) & 81.4 (76.2 to 86.6$)$ & 80.9 (75.2 to 86.6$)$ \\
\hline Difference & $-7.8(-15.2$ to -0.4$)$ & $-6.7(-12.1$ to -1.2$)$ & $-7.5(-13.4$ to -1.5$)$ \\
\hline$p$-value & $0.0388^{*}$ & $0.0162^{*}$ & $0.0142^{*}$ \\
\hline \multicolumn{4}{|c|}{ Role Functioning Emotional } \\
\hline Home & $84.8(82.6$ to 87.0$)$ & 95.0 (93.7 to 96.3 ) & 94.6 (93.2 to 96.1$)$ \\
\hline $\mathrm{CH}$ & 84.0 (77.0 to 91.0$)$ & 92.5 (88.3 to 96.7 ) & 92.9 (88.1 to 97.7$)$ \\
\hline Difference & $-0.8(-8.1$ to 6.6$)$ & $-2.5(-6.9$ to 1.9$)$ & $-1.8(-6.8$ to 3.3$)$ \\
\hline$p$-value & 0.8364 & 0.2716 & 0.4913 \\
\hline
\end{tabular}


Table III. (Contd...)

\begin{tabular}{|c|c|c|c|}
\hline \multirow[t]{2}{*}{ Variable } & \multicolumn{3}{|c|}{ Mean $(95 \% \mathrm{Cl})$} \\
\hline & Preoperative & 6-mth follow-up ( $n=1,065)$ & 2-yr follow-up ( $n=879$ ) \\
\hline \multicolumn{4}{|l|}{ Mental Health } \\
\hline Home & 79.9 (78.8 to 81.0$)$ & 84.8 (83.8 to 85.7$)$ & 85.8 (84.7 to 86.8$)$ \\
\hline $\mathrm{CH}$ & 77.4 (74.1 to 80.8$)$ & 81.6 (78.6 to 84.6$)$ & 82.8 (79.4 to 86.2 ) \\
\hline Difference & $-2.5(-6.0$ to 1.0$)$ & $-3.2(-6.3$ to 0.0$)$ & $-3.0(-6.5$ to 0.6$)$ \\
\hline$p$-value & 0.1648 & $0.0467^{*}$ & 0.0986 \\
\hline \multicolumn{4}{|l|}{ OKS } \\
\hline Home & 34.2 (33.7 to 34.7 ) & 19.6 (19.3 to 20.0 ) & 18.5 (18.1 to 18.9 ) \\
\hline $\mathrm{CH}$ & 35.8 (34.2 to 37.3 ) & 21.5 (20.3 to 22.6 ) & 22.0 (20.9 to 23.2 ) \\
\hline Difference & 1.5 (-0.1 to 3.2$)$ & 1.8 (0.6 to 3.0$)$ & 3.5 (2.3 to 4.8$)$ \\
\hline $\mathrm{p}$-value & 0.0660 & 0.0030 & $<0.0001$ \\
\hline
\end{tabular}

${ }^{*} \mathrm{p}<0.05$ was considered statistically significant. Cl: confidence interval; KSCRS: Knee Society Clinical Rating System; OKS: Oxford Knee Score; SF-36: 36-item Short Form Health Survey

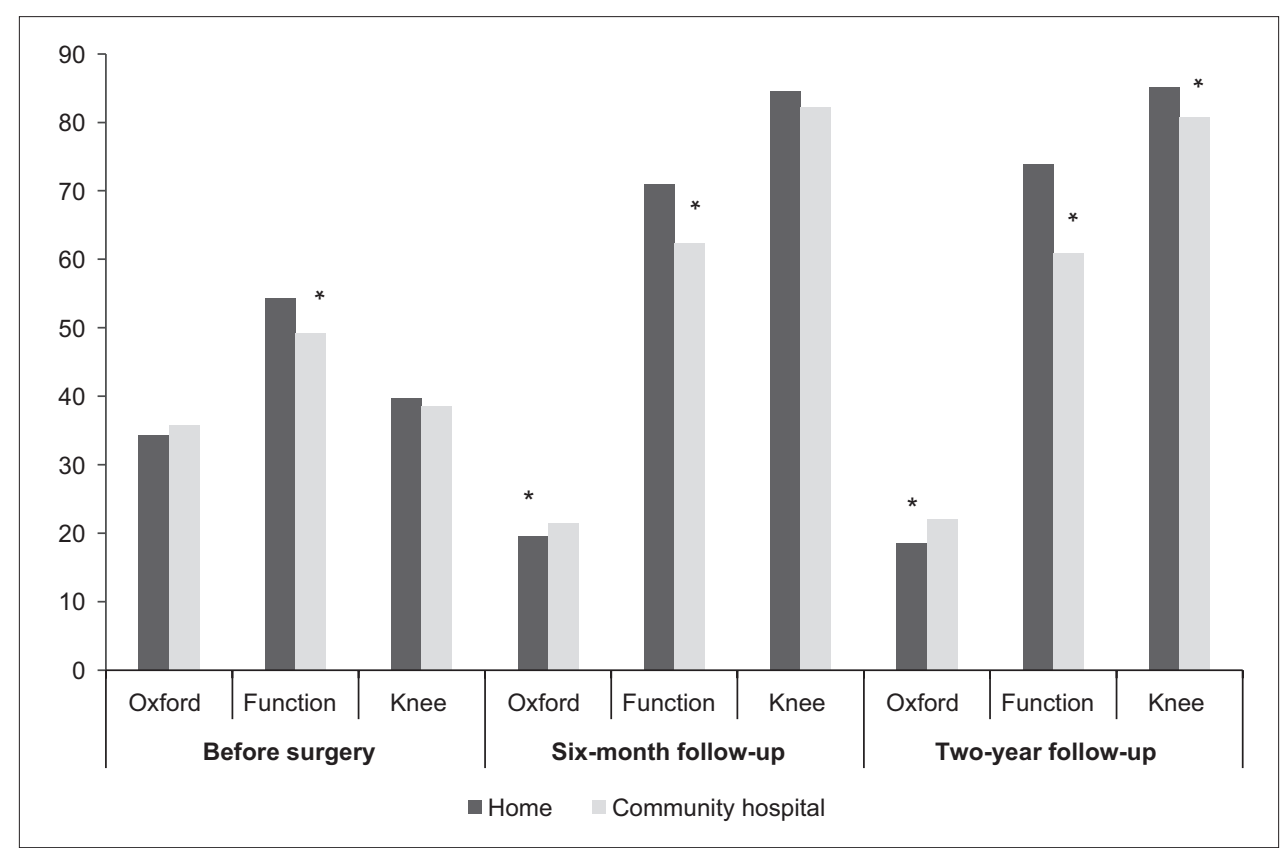

Fig. 3 Chart shows mean scores of Oxford Knee Score (Oxford) and Knee Society Clinical Rating System (KSCRS) over two years for home and community hospital patients who underwent total knee arthroplasty. ${ }^{*}$ Difference between home and community hospital patients was statistically significant. Function: KSCRS Function; Knee: KSCRS Knee

(28.9 vs. 22.8; $\mathrm{p}=0.0282$ ), Role Functioning Physical (48.1 vs. 35.5; $p=0.0216)$ and General Health (0.1 vs. $-5.2 ; p=0.0386)$, and OKS (-15.6 vs. $-13.7 ; p=0.0359)$ scores (Table IV).

With repeated ANOVA accounting for preoperative differences as confounders, discharge destination was found to be significantly associated with KSCRS Function $(p=0.0037)$ and Knee ( $p=0.0228)$, SF-36 Physical Functioning $(p=0.0146)$ and OKS ( $p=0.0006)$. In other words, discharge destination independently affected KSCRS Function and Knee, SF-36 Physical Functioning and OKS, after taking into account preoperative differences in age, gender, educational level and physical health of patients (Table V).

Repeated ANOVA showed that patient age was a significant covariate for KSCRS Function $(p<0.0001)$ and Knee $(p=0.0118)$, and SF-36 Physical Functioning $(p<0.0001)$ and Social Functioning $(p=0.0029)$. Similarly, gender was a significant covariate for KSCRS Function ( $p=0.0007)$ and Knee $(p=0.0122)$, OKS ( $p=0.0028)$, and SF-36 Physical Functioning $(p=0.0004)$, Pain $(p=0.0022)$, General Health $(p=0.0481)$, Vitality $(p<0.0001)$ and Mental Health $(p=0.0441)$. Educational level was significantly associated with KSCRS Function $(p<0.0001)$ and Knee ( $p=0.0167)$, and SF-36 Physical Functioning ( $p$ $=0.0030$ ). The presence of more than one comorbidity was significantly associated with KSCRS Function $(p=0.0051)$, OKS $(p=0.0034)$, and SF-36 Physical Functioning $(p=0.0062)$, Role Functioning Physical $(p=0.0255)$ and Vitality $(p=0.0119)$.

\section{DISCUSSION}

It is essential to analyse the predictors of discharge destination, as the factors identified would allow surgeons to correctly determine which patient is likely to require subacute care in $\mathrm{CHs}$, thus minimising unnecessary healthcare expenditure. In addition, 
Table IV. Improvement in functional outcome measures of patients discharged home and to community hospitals (CHs) following total knee arthroplasty over the study period.

\begin{tabular}{|c|c|c|}
\hline \multirow[t]{2}{*}{ Variable } & \multicolumn{2}{|c|}{ Mean $(95 \% \mathrm{Cl}) *$} \\
\hline & 6-mth follow-up (n=1,065) & 2-yr follow-up $(n=879)$ \\
\hline \multicolumn{3}{|l|}{ KSCRS domain } \\
\hline \multicolumn{3}{|l|}{ Function } \\
\hline Home & 16.6 (15.4 to 17.8$)$ & 19.5 (18.2 to 20.7$)$ \\
\hline $\mathrm{CH}$ & 13.1 (9.3 to 16.9$)$ & $11.6(7.5$ to 15.8$)$ \\
\hline Difference & $3.5(-0.4$ to 7.5$)$ & $7.8(3.5$ to 12.1$)$ \\
\hline$p$-value & 0.0797 & $0.0004^{\dagger}$ \\
\hline \multicolumn{3}{|l|}{ Knee } \\
\hline Home & 44.9 (43.6 to 46.3$)$ & 45.2 (43.9 to 46.6$)$ \\
\hline $\mathrm{CH}$ & 43.6 (39.4 to 47.7$)$ & 42.4 (38.0 to 46.7$)$ \\
\hline Difference & $1.4(-3.0$ to 5.8$)$ & $2.9(-1.7$ to 7.4$)$ \\
\hline$p$-value & 0.5376 & 0.2177 \\
\hline \multicolumn{3}{|l|}{ SF-36 domain } \\
\hline \multicolumn{3}{|c|}{ Physical Functioning } \\
\hline Home & 26.5 (25.0 to 28.0 ) & 28.9 (27.3 to 30.6$)$ \\
\hline $\mathrm{CH}$ & 24.7 (20.1 to 29.4$)$ & $22.8(17.5$ to 28.0$)$ \\
\hline Difference & $1.7(-3.1$ to 6.6$)$ & $6.2(0.7$ to 11.7$)$ \\
\hline$p$-value & 0.4821 & $0.0282^{+}$ \\
\hline \multicolumn{3}{|c|}{ Role Functioning Physical } \\
\hline Home & 48.9 (45.9 to 51.9$)$ & 48.1 (44.9 to 51.3 ) \\
\hline $\mathrm{CH}$ & 40.3 (30.9 to 49.7 ) & 35.5 (25.3 to 45.7$)$ \\
\hline Difference & $8.6(-1.3$ to 18.5$)$ & 12.6 (1.9 to 23.3$)$ \\
\hline$p$-value & 0.0884 & $0.0216^{+}$ \\
\hline \multicolumn{3}{|l|}{ Pain } \\
\hline Home & $33.0(31.3$ to 34.7$)$ & $32.0(30.2$ to 33.9$)$ \\
\hline $\mathrm{CH}$ & $27.0(21.7$ to 32.3$)$ & 26.9 (21.0 to 32.8$)$ \\
\hline Difference & 6.0 (0.4 to 11.5$)$ & $5.1(-1.1$ to 11.3$)$ \\
\hline$p$-value & $0.0346^{\dagger}$ & 0.1050 \\
\hline \multicolumn{3}{|c|}{ General Health } \\
\hline Home & $-0.9(-2.3$ to 0.4$)$ & $0.1(-1.4$ to 1.6$)$ \\
\hline $\mathrm{CH}$ & $-1.6(-5.7$ to 2.6$)$ & $-5.2(-10.0$ to -0.4$)$ \\
\hline Difference & $0.6(-3.7$ to 5.0$)$ & $5.3(0.3$ to 10.4$)$ \\
\hline$p$-value & 0.7751 & $0.0386^{\dagger}$ \\
\hline \multicolumn{3}{|l|}{ Vitality } \\
\hline Home & $3.6(2.3$ to 5.0$)$ & 4.4 (2.7 to 6.0$)$ \\
\hline $\mathrm{CH}$ & $3.2(-1.1$ to 7.6$)$ & $5.7(0.5$ to 10.9$)$ \\
\hline Difference & $0.4(-4.1$ to 5.0$)$ & $-1.3(-6.8$ to 4.2$)$ \\
\hline$p$-value & 0.8515 & 0.6368 \\
\hline \multicolumn{3}{|c|}{ Social Functioning } \\
\hline Home & 32.1 (29.6 to 34.5$)$ & $31.8(29.2$ to 34.4$)$ \\
\hline $\mathrm{CH}$ & 33.2 (25.4 to 40.9$)$ & $31.6(23.3$ to 40.0$)$ \\
\hline Difference & $-1.1(-9.3$ to 7.0$)$ & 0.2 (-8.6 to 8.9$)$ \\
\hline$p$-value & 0.7889 & 0.9719 \\
\hline \multicolumn{3}{|c|}{ Role Functioning Emotional } \\
\hline Home & $10.2(7.9$ to 12.6$)$ & 9.7 (7.1 to 12.2$)$ \\
\hline $\mathrm{CH}$ & 8.5 (1.1 to 15.9$)$ & $9.6(1.5$ to 17.7$)$ \\
\hline Difference & 1.7 (-6.0 to 9.4$)$ & $0.1(-8.4$ to 8.5$)$ \\
\hline$p$-value & 0.6640 & 0.9865 \\
\hline
\end{tabular}


Table IV. (Contd..)

\begin{tabular}{|c|c|c|}
\hline \multirow[t]{2}{*}{ Variable } & \multicolumn{2}{|c|}{ Mean $(95 \% \mathrm{Cl}) *$} \\
\hline & 6-mth follow-up $(n=1,065)$ & 2-yr follow-up $(n=879)$ \\
\hline \multicolumn{3}{|l|}{ Mental Health } \\
\hline Home & 4.9 (3.8 to 6.0$)$ & 6.0 (4.7 to 7.2$)$ \\
\hline $\mathrm{CH}$ & $4.2(0.7$ to 7.6$)$ & 5.6 (1.6 to 9.5$)$ \\
\hline Difference & $0.7(-2.9$ to 4.3$)$ & $0.4(-3.7$ to 4.5$)$ \\
\hline$p$-value & 0.7042 & 0.8477 \\
\hline \multicolumn{3}{|l|}{ OKS } \\
\hline Home & $-14.6(-15.1$ to -14.0$)$ & $-15.6(-16.1$ to -15.1$)$ \\
\hline $\mathrm{CH}$ & $-14.3(-15.9$ to -12.6$)$ & $-13.7(-15.4$ to -12.0$)$ \\
\hline Difference & $-0.3(-2.0$ to 1.4$)$ & $-1.9(-3.6$ to -0.1$)$ \\
\hline $\mathrm{p}$-value & 0.7401 & $0.0359^{\dagger}$ \\
\hline
\end{tabular}

*Refers to the difference between preoperative and follow-up measurements. $t p<0.05$ was considered statistically significant. Cl: confidence interval; KSCRS: Knee Society Clinical Rating System; OKS: Oxford Knee Score; SF-36: 36-item Short Form Health Survey

surgeons may be inclined to shorten the patient's LOS, arriving at early decisions about patient discharge perhaps even before patient outcome can be clearly predicted, leading to unwarranted discharge from inpatient rehabilitation. ${ }^{(23)}$ The findings of studies such as ours could, therefore, aid in the proper subacute care of patients following TKA.

We found that older, less educated, female patients and those with lower preoperative functional scores were more likely to be discharged to $\mathrm{CH}$ s following TKA. In the reported literature, older age, female gender, poorer social support and higher American Society of Anesthesiologists (ASA) score for physical status were the most frequently analysed predictors of discharge to $\mathrm{CHs}$, with varying results. ${ }^{(6,8,9,24,25)}$ Our study did not show differences in comorbidities and postoperative complications between patients discharged home and to $\mathrm{CHs}$, unlike other studies. ${ }^{(8,26}$ One possible reason could be that in our local context, patients were discharged to $\mathrm{CHs}$ primarily for social reasons and not to optimise their medical conditions, so there was unlikely to be any significant difference in terms of comorbidities and postoperative complications between patients discharged home or to $\mathrm{CH}$.

In the reported literature, Bozic et al identified older age, female gender and higher ASA scores to be significant predictors. ${ }^{(24)}$ Tribe et al reported a higher proportion of women in the inpatient rehabilitation group, although they found no difference between various discharge destinations with respect to age, social support and disease duration. ${ }^{(9)}$ Kelly and Ackerman reported that patients discharged to subacute care were older, and had poor social support (lived alone) and increased comorbidities, while gender had no predictive value on discharge destination. ${ }^{\left({ }^{(8)}\right.}$ Mallinson et al found that older age, and decreased functional mobility and independence were predictors of being sent to skilled nursing facilities or inpatient rehabilitation facilities. ${ }^{(6)}$ Sharareh et al reported that higher ASA scores, slower 'Timed Get Up and Go' time, lower EuroQoL Quality of Life Scale (EQ-5D) scores, poor social status (living alone), increased LOS, increased postoperative pain and decreased distances walked on PD 1 correlated with being discharged to skilled nursing facilities. ${ }^{(27)}$
The rationale for discharging older patients with worse preoperative status to $\mathrm{CHs}$ for rehabilitation includes the presence of 24-hour care and easier access to rehabilitation. ${ }^{(11)}$ However, despite more attention and care being given, this group of patients did not show as much improvement as patients discharged home. Based on the KSCRS, our $\mathrm{CH}$ patients had lower functional outcomes prior to surgery, and when compared to patients who were discharged home, the difference in functional outcomes further widened over the two years of follow-up. In terms of SF-36 scores, which were also worse for $\mathrm{CH}$ patients preoperatively, the gaps widened between the pre- and postoperative scores at the six-month and two-year follow-ups. For OKS, although there was no difference preoperatively, patients discharged to $\mathrm{CHs}$ did worse overall at the two-year follow-up. In our study, postoperative functional outcomes at six months and two years were used to reflect the effects of rehabilitation in subacute care and the long-term progression of patients after all of them returned home, respectively. Since patients discharged to $\mathrm{CH}$ s continued to do worse in most functional outcome measures at two years, it is possible that there were other factors besides discharge destination that made them less functionally capable than patients discharged home. Possible factors identified in our study were age, gender, educational level and pre-existing comorbidities.

There were several reasons that could have accounted for the differences in functional outcomes seen between our patients discharged home and to $\mathrm{CHs}$. Firstly, patients discharged home would be more independent than those discharged to $\mathrm{CHs}$, as the former group were more likely to be active (e.g. walking to the toilet, getting out of bed or the house, shopping) and the home might be a more optimal rehabilitation environment compared with an institutional setting. ${ }^{(5,6)}$ Studies have reported a growing volume of literature that shows that discharging patients directly home following arthroplasty surgery is beneficial. ${ }^{(6,11)}$ Secondly, many patients discharged to $\mathrm{CHs}$ may have had poor social support - they may not have been as well taken care of or may have had less motivation to improve after discharge from $\mathrm{CHs}$ (given that median LOS in CHs was only 23.0 days in our study) and therefore, more difficulty in acquiring functional ability. This 
Table V. Repeated analysis of variance for association between functional outcomes and other covariates.

\begin{tabular}{|c|c|c|}
\hline Variable & Estimate (SE) & p-value \\
\hline \multicolumn{3}{|l|}{ KSCRS domain } \\
\hline \multicolumn{3}{|l|}{ Function } \\
\hline $\begin{array}{l}\text { Discharge destination } \\
\text { (reference: home) }\end{array}$ & $-4.42(1.52)$ & 0.0037 \\
\hline Age & $-0.41(0.06)$ & $<0.0001$ \\
\hline Gender (reference: male) & $-3.71(1.09)$ & 0.0007 \\
\hline Education (reference: tertiary) & & $<0.0001$ \\
\hline None & $-8.03(1.87)$ & $<0.0001$ \\
\hline Primary & $-4.30(1.76)$ & 0.0146 \\
\hline Secondary & $-3.01(1.78)$ & 0.0907 \\
\hline Comorbidity (reference: yes) & $3.36(1.20)$ & 0.0051 \\
\hline \multicolumn{3}{|l|}{ Knee } \\
\hline $\begin{array}{l}\text { Discharge destination } \\
\text { (reference: home) }\end{array}$ & $-2.42(1.06)$ & 0.0228 \\
\hline Age & $0.11(0.04)$ & 0.0118 \\
\hline Gender (reference: male) & $-1.91(0.76)$ & 0.0122 \\
\hline Education (reference: tertiary) & & $0.0167^{*}$ \\
\hline None & $-3.10(1.30)$ & 0.0170 \\
\hline Primary & $-3.20(1.22)$ & 0.0088 \\
\hline Secondary & $-1.54(1.23)$ & 0.2116 \\
\hline Comorbidity (reference: yes) & $0.53(0.83)$ & 0.5283 \\
\hline \multicolumn{3}{|l|}{ SF-36 domain } \\
\hline \multicolumn{3}{|l|}{ Physical Functioning } \\
\hline $\begin{array}{l}\text { Discharge destination } \\
\text { (reference: home) }\end{array}$ & $-4.51(1.84)$ & 0.0146 \\
\hline Age & $-0.41(0.07)$ & $<0.0001$ \\
\hline Gender (reference: male) & $-4.76(1.33)$ & 0.0004 \\
\hline Education (reference: tertiary) & & $0.0030^{*}$ \\
\hline None & $-7.52(2.27)$ & 0.0009 \\
\hline Primary & $-3.97(2.13)$ & 0.0634 \\
\hline Secondary & $-3.12(2.15)$ & 0.1471 \\
\hline Comorbidity (reference: yes) & $3.99(1.45)$ & 0.0062 \\
\hline \multicolumn{3}{|l|}{ OKS } \\
\hline $\begin{array}{l}\text { Discharge destination } \\
\text { (reference: home) }\end{array}$ & $1.78(0.52)$ & 0.0006 \\
\hline Age & $0.03(0.02)$ & 0.1836 \\
\hline Gender (reference: male) & $1.11(0.37)$ & 0.0028 \\
\hline Education (reference: tertiary) & & $0.0941^{*}$ \\
\hline None & $1.43(0.63)$ & 0.0234 \\
\hline Primary & $0.96(0.59)$ & 0.1050 \\
\hline Secondary & $0.62(0.60)$ & 0.2998 \\
\hline Comorbidity (reference: yes) & $-1.19(0.41)$ & 0.0034 \\
\hline
\end{tabular}

*Refers to Type III p-value. KSCRS: Knee Society Clinical Rating System; OKS: Oxford Knee Score; SE: standard error; SF-36: 36-item Short Form Health Survey

was also seen in other studies, which reported increased frequency of falls in patients who live alone..$^{(6,9,13)}$ Thirdly, patients discharged to $\mathrm{CH}$ s had lower baseline levels of physical function and may have been less capable of rehabilitation. This aside, our statistical analysis showed that despite poorer preoperative functional levels, being discharged to $\mathrm{CHs}$ after surgery was an independent factor for less improvement when compared to being discharged home. Lastly, it is possible that the rehabilitation programme in $\mathrm{CH}$ s did not meet the needs of this group of patients and the $\mathrm{CH}$ s were not ready to provide the best rehabilitation achievable. Even if true, given the general improved quality of rehabilitation in $\mathrm{CHs}$ over time, this last factor is unlikely to hold sway for long.

We did not analyse LOS in acute hospitals as one of the variables determining functional outcomes because patients discharged to $\mathrm{CHs}$ may stay longer in the acute hospitals while waiting for placement. Neither did we analyse LOS in $\mathrm{CHs}$ because patients may have had many reasons for extending their stay (e.g. social reasons or other illnesses besides rehabilitation). We acknowledge the importance of LOS vis-à-vis cost analysis, as subacute care may be more expensive $e^{(8,9,11,14)}$ due to inpatient costs. For instance, in our tertiary institution, the 50th percentile bill size is SGD 19,861 for an average hospital stay of 4.4 days following TKA. ${ }^{(28)}$ Generally, ward charges in CHs are SGD 338390 per day. ${ }^{(29)}$ Given that the median LOS in CHs was 23.0 days, our patients would have spent an additional SGD 7,774-8,970 in subacute care, in addition to the cost incurred at the acute hospital. This is more than what a typical patient discharged home would pay for outpatient physiotherapy (approximately SGD 375 for five physiotherapy sessions during a four-week period at the time of this study). Furthermore, in our local context, patients may have stayed in primary care longer than needed, as confirmed placement in $\mathrm{CHs}$ and other administrative duties tend to take time. Therefore, apart from the smaller improvement seen among patients discharged to $\mathrm{CH}$ s compared to those discharged home, $\mathrm{CH}$ stay was also not cost-effective. This suggests that we may need to explore the feasibility of other forms of monitored subacute rehabilitation, such as home visits or tele-rehabilitation, which have recently been reported to play a useful role $\mathrm{e}^{(30)}$ for patients following TKA.

In summary, we have identified several predictors of discharge destination (i.e. old age, female gender, lower educational level, poorer preoperative functional scores). These would allow surgeons to educate and prepare patients regarding proper subacute care and cost estimation. With regard to functional outcomes, the current literature provided varying results for inpatient rehabilitation and home rehabilitation..$^{(5-11)}$ Our study which to our knowledge is the largest of its kind with the longest follow-up time comparing patients who were discharged home or to $\mathrm{CH}$ s following TKA (Table VI) - favours discharging patients home directly after TKA, given the superior functional outcomes and cost-effectiveness seen among these patients. Still, $\mathrm{CHs}$ play a strong role in our local community. Firstly, inpatient rehabilitation in $\mathrm{CHs}$ may be the optimal postoperative destination for patients with postoperative complications that require 24-hour healthcare support. ${ }^{(11,13)}$ Secondly, in our local context, social reasons play a big part in choosing $\mathrm{CH}$ s as the discharge destination, as many patients do not have family members who are able to take care of them in the day.

Our study was limited on various fronts. Even though the majority of our patients were present at the six-month follow-up, a fair number of them were lost to follow-up at two years (186/1,065; 
Table VI. Studies in the English language literature that have compared functional outcomes following total knee arthroplasty between patients with different discharge destinations.

\begin{tabular}{|c|c|c|c|c|c|}
\hline Study, yr & $\begin{array}{l}\text { No. of } \\
\text { patients }\end{array}$ & $\begin{array}{l}\text { Duration of } \\
\text { follow-up }\end{array}$ & Patient group & $\begin{array}{l}\text { Functional outcome } \\
\text { measurement }\end{array}$ & Finding \\
\hline $\begin{array}{l}\text { Shepperd } \\
\text { et } \mathrm{al}^{(7)} 1998\end{array}$ & 86 & $3 \mathrm{mth}$ & $\begin{array}{l}\text { Inpatient rehabilitation, } \\
\text { home rehabilitation }\end{array}$ & $\begin{array}{l}\text { SF-36, Dartmouth } \\
\text { COOP chart, Bristol } \\
\text { Knee Score }\end{array}$ & $\begin{array}{l}\text { No significant differences in } \\
\text { functional outcomes were } \\
\text { recorded. However, more } \\
\text { patients in the inpatient group } \\
\text { reported that they had received } \\
\text { the preferred form of care. }\end{array}$ \\
\hline $\begin{array}{l}\text { Kelly and } \\
\text { Ackerman, }{ }^{(8)} \\
1999\end{array}$ & 96 & $1 \mathrm{mth}$ and $3 \mathrm{mth}$ & $\begin{array}{l}\text { Subacute rehabilitation, } \\
\text { home rehabilitation }\end{array}$ & $\begin{array}{l}\text { Self-administered joint } \\
\text { rating questionnaire }\end{array}$ & $\begin{array}{l}\text { Patients discharged home had } \\
\text { higher mean functional score } \\
\text { over } 3 \text { mth. }\end{array}$ \\
\hline $\begin{array}{l}\text { Tribe et al, }{ }^{(9)} \\
2005\end{array}$ & 70 & $12 \mathrm{mth}$ & $\begin{array}{l}\text { Inpatient rehabilitation, } \\
\text { homecare services }\end{array}$ & SF-36, WOMAC scores & $\begin{array}{l}\text { No difference in functional } \\
\text { outcomes between home and } \\
\text { inpatient rehabilitation groups. }\end{array}$ \\
\hline $\begin{array}{l}\text { Chimenti } \\
\text { and } \\
\text { Ingersoll,,(10) } \\
2007\end{array}$ & 212 & $\begin{array}{l}\text { Upon discharge } \\
\text { from inpatient } \\
\text { or outpatient } \\
\text { rehabilitation }\end{array}$ & $\begin{array}{l}\text { Subacute rehabilitation, } \\
\text { home health services }\end{array}$ & $\begin{array}{l}\text { Pain, range of motion, } \\
\text { extension lag, use of } \\
\text { assistive device }\end{array}$ & $\begin{array}{l}\text { Increased improvement in } \\
\text { extension lag for patients } \\
\text { discharged home compared to } \\
\text { patients discharged to subacute } \\
\text { care. No other differences in } \\
\text { functional outcomes seen. }\end{array}$ \\
\hline $\begin{array}{l}\text { Mahomed } \\
\text { et } \mathrm{al}^{(11)} 2008\end{array}$ & 234 & $3 \mathrm{mth}$ and $12 \mathrm{mth}$ & $\begin{array}{l}\text { Subacute rehabilitation, } \\
\text { homecare services }\end{array}$ & $\begin{array}{l}\text { SF-36, WOMAC, patient } \\
\text { satisfaction scores }\end{array}$ & $\begin{array}{l}\text { No difference in pain, functional } \\
\text { outcomes or patient satisfaction } \\
\text { between home-based or } \\
\text { inpatient rehabilitation. }\end{array}$ \\
\hline $\begin{array}{l}\text { Mallinson } \\
\text { et al, }{ }^{(6)} 2011\end{array}$ & 146 & $\begin{array}{l}\text { Upon discharge } \\
\text { from inpatient } \\
\text { or outpatient } \\
\text { rehabilitation }\end{array}$ & $\begin{array}{l}\text { Inpatient rehabilitation } \\
\text { facilities, skilled nursing } \\
\text { facilities, home health } \\
\text { agencies }\end{array}$ & $\begin{array}{l}\text { Inpatient rehabilitation } \\
\text { facility patient } \\
\text { assessment instrument }\end{array}$ & $\begin{array}{l}\text { Patients discharged to home } \\
\text { health agencies had better } \\
\text { preoperative and postoperative } \\
\text { self-care and mobility scores } \\
\text { compared to those discharged } \\
\text { to inpatient rehabilitation } \\
\text { facilities. }\end{array}$ \\
\hline $\begin{array}{l}\text { Present } \\
\text { study, } 2018\end{array}$ & 1,065 & $6 \mathrm{mth}$ and $2 \mathrm{yr}$ & $\begin{array}{l}\text { Community hospital } \\
\text { rehabilitation, home } \\
\text { rehabilitation }\end{array}$ & KSCRS, SF-36, OKS & $\begin{array}{l}\text { Patients discharged home had } \\
\text { better postoperative functional } \\
\text { outcomes (KSCRS, SF-36, OKS). }\end{array}$ \\
\hline
\end{tabular}

COOP: Cooperative Functional Assessment; KSCRS: Knee Society Clinical Rating System; OKS: Oxford Knee Score; SF-36: 36-item Short Form Health Survey; WOMAC: Western Ontario and McMaster Universities Osteoarthritis Index

$17.5 \%$ ). A majority of these patients could not be contacted; thus, the exact reasons for their default of follow-up sessions remain unknown. As this was a retrospective study, it is possible that healthcare personnel may not have regularly contacted these patients. Also, the patient's support system should have ideally been assessed, including caregiver status and financial support. Furthermore, functional outcomes at the point-of-discharge from the acute hospital could have been collected and compared between patients discharged to $\mathrm{CHs}$ and home to further evaluate the amount of improvement seen after surgery. Lastly, our study focused mainly on the local context, and so further long-term studies comparing the similarities and application of our findings to overseas institutions would be beneficial.

In conclusion, older, female and less educated patients with poorer preoperative functional scores were more likely to be discharged to $\mathrm{CHs}$ for continued subacute care after TKA. At the two-year follow-up, patients who had extended inpatient rehabilitation in $\mathrm{CHs}$ had less improvement in functional outcomes when compared to those discharged home.

\section{REFERENCES}

1. Ethgen $O$, Bruyere O, Richy F, Dardennes C, Reginster JY. Health-related quality of life in total hip and total knee arthroplasty. A qualitative and systematic review of the literature. J Bone Joint Surg Am 2004; 86-A:963-74.

2. Fransen $M$, Bridgett $L$, March L, et al. The epidemiology of osteoarthritis in Asia. Int J Rheum Dis 2011; 14:113-21.

3. Singh JA. Epidemiology of knee and hip arthroplasty: a systematic review. Open Orthop J 2011; 5:80-5.

4. Jain NB, Higgins LD, Ozumba D, et al. Trends in epidemiology of knee arthroplasty in the United States, 1990-2000. Arthritis Rheum 2005; 52:3928-33.

5. Kathrins B, Kathrins R, Marsico R, et al. Comparison of day rehabilitation to skilled nursing facility for the rehabilitation for total knee arthroplasty. Am J Phys Med Rehabil 2013; 92:61-7.

6. Mallinson TR, Bateman J, Tseng HY, et al. A comparison of discharge functional status after rehabilitation in skilled nursing, home health, and medical rehabilitation settings for patients after lower-extremity joint replacement surgery. Arch Phys Med Rehabil 2011; 92:712-20.

7. Shepperd S, Harwood D, Jenkinson C, et al. Randomised controlled trial comparing hospital at home care with inpatient hospital care. I: three month follow up of health outcomes. BMJ 1998; 316:1786-91.

8. Kelly MH, Ackerman RM. Total joint arthroplasty: a comparison of postacute settings on patient functional outcomes. Orthop Nurs 1999; 18:75-84.

9. Tribe KL, Lapsley HM, Cross MJ, et al. Selection of patients for inpatient rehabilitation or direct home discharge following total joint replacement surgery: a comparison of health status and out-of-pocket expenditure of patients 
undergoing hip and knee arthroplasty for osteoarthritis. Chronic IIIn 2005; 1:289-302.

10. Chimenti CE, Ingersoll G. Comparison of home health care physical therapy outcomes following total knee replacement with and without subacute rehabilitation. J Geriatr Phys Ther 2007; 30:102-8.

11. Mahomed NN, Davis AM, Hawker G, et al. Inpatient compared with homebased rehabilitation following primary unilateral total hip or knee replacement: a randomized controlled trial. J Bone Joint Surg Am 2008; 90:1673-80.

12. Chen AW, Koh YT, Leong SW, et al. Post community hospital discharge rehabilitation attendance: self-perceived barriers and participation over time. Ann Acad Med Singapore 2014; 43:136-44.

13. Chen C, Koh GC, Naidoo N, et al. Trends in length of stay, functional outcomes, and discharge destination stratified by disease type for inpatient rehabilitation in Singapore community hospitals from 1996 to 2005. Arch Phys Med Rehabil 2013; 94:1342-51.e4.

14. Roos EM. Effectiveness and practice variation of rehabilitation after joint replacement. Curr Opin Rheumatol 2003; 15:160-2.

15. Labraca NS, Castro-Sánchez AM, Matarán-Peñarrocha GA, et al. Benefits of starting rehabilitation within 24 hours of primary total knee arthroplasty: randomized clinical trial. Clin Rehabil 2011; 25:557-66.

16. Larsen K, Hansen TB, Søballe K, Kehlet H. Patient-reported outcome after fasttrack knee arthroplasty. Knee Surg Sports Traumatol Arthrosc 2012; 20:1128-35

17. Husted H, Jensen CM, Solgaard S, Kehlet H. Reduced length of stay following hip and knee arthroplasty in Denmark 2000-2009: from research to implementation. Arch Orthop Trauma Surg 2012; 132:101-4.

18. Tan C, Loo G, Pua YH, et al. Predicting discharge outcomes after total knee replacement using the Risk Assessment and Predictor Tool. Physiotherapy 2014; 100:176-81.

19. Thumboo J, Fong KY, Machin D, et al. A community-based study of scaling assumptions and construct validity of the English (UK) and Chinese (HK) SF-36 in Singapore. Qual Life Res 2001; 10:175-88.

20. Ko Y, Lo NN, Yeo SJ, et al. Comparison of the responsiveness of the SF-36, the
Oxford Knee Score, and the Knee Society Clinical Rating System in patients undergoing total knee replacement. Qual Life Res 2013; 22:2455-9.

21. Xie F, Li SC, Lo NN, et al. Cross-cultural adaptation and validation of Singapore English and Chinese Versions of the Oxford Knee Score (OKS) in knee osteoarthritis patients undergoing total knee replacement. Osteoarthritis Cartilage 2007; 15: 1019-24.

22. Escobar A, Quintana JM, Bilbao A, et al. Responsiveness and clinically important differences for the WOMAC and SF-36 after total knee replacement. Osteoarthritis Cartilage 2007; 15:273-80.

23. Oldmeadow LB, McBurney H, Robertson VJ. Hospital stay and discharge outcomes after knee arthroplasty: implications for physiotherapy practice. Aust J Physiother 2002; 48:117-21.

24. Bozic KJ, Wagie A, Naessens JM, Berry DJ, Rubash HE. Predictors of discharge to an inpatient extended care facility after total hip or knee arthroplasty. J Arthroplasty 2006; 21(6 Suppl 2):151-6.

25. Oldmeadow LB, McBurney H, Robertson VJ. Predicting risk of extended inpatient rehabilitation after hip or knee arthroplasty. J Arthroplasty 2003; 18:775-9.

26. Barsoum WK, Murray TG, Klika AK, et al. Predicting patient discharge disposition after total joint arthroplasty in the United States. J Arthroplasty 2010; 25:885-92.

27. Sharareh B, Le NB, Hoang MT, Schwarzkopf R. Factors determining discharge destination for patients undergoing total joint arthroplasty. J Arthroplasty 2014; 29:13558.e1.

28. Ministry of Health, Singapore. Knee replacement surgery. Available at: https:// www.moh.gov.sg/content/moh_web/home/costs_and_financing/hospitalcharges/Total-Hospital-Bills-By-condition-procedure/knee_replacementsurgery. html. Accessed February 21, 2016

29. Ang Mo Kio - Thye Hua Kwan Hospital, Singapore. Ward Type and Charges. In: Your Stay with Us [online]. Available at: http://www.amkh.com.sg/stay-with-us. Accessed August 8, 2018.

30. Tousignant $M$, Moffet $H$, Boissy $P$, et al. A randomized controlled trial of home telerehabilitation for post-knee arthroplasty. J Telemed Telecare 2011; 17:195-8. 